\title{
Increased Prevalence of JC Polyomavirus in Cervical Carcinomas from Women Infected with HIV
}

\author{
Bandar Alosaimi, ${ }^{1}$ Lynne Hampson, ${ }^{1}$ Xiaotong He, ${ }^{1}$ Innocent O. Maranga, ${ }^{2}$ Anthony. W. Oliver, ${ }^{1}$ \\ and Ian N. Hampson ${ }^{1 *}$ \\ ${ }^{1}$ Viral Oncology Laboratories, University of Manchester Institute of Cancer Sciences, Manchester, UK \\ ${ }^{2}$ Department of Obstetrics and Gynaecology, University of Nairobi, Kenyatta National Hospital, Nairobi, Kenya
}

\begin{abstract}
Although subclinical persistent infections with the human polyomaviruses BKV and JCV are ubiquitous worldwide, these are known to vary in relation to diseases present and geographical location. DNAs from 220 cervical smears and 109 invasive cervical carcinomas obtained from HIV positive and HIV negative Kenyan women of known HPV status were analyzed by nested endpoint PCR for BKV and JCV. BKV-JCV DNA was detected in $5 / 105(4.7 \%)$ of cervical smears and in $6 / 37(16 \%)$ of cervical carcinomas from women infected with HIV whereas 9/115 (7.8\%) of the cervical smears and $4 / 72(5.5 \%)$ of the carcinomas were positive in HIV negative women. Nested PCR showed that all 24 samples were positive for JCV and not BKV. JCV was not more prevalent in either HPV positive $(P=0.438)$ or HPV negative women $(P=0.392)$. However, $37 \%$ of carcinomas and smears which were positive for JCV were also positive for a "high-risk" oncogenic HPV. Comparison of the incidence of JCV in cervical smears and cervical carcinomas showed a $\sim 3$-fold increase in samples from HIV positive women with cervical carcinoma $(P=0.025)$ whereas no significant difference was found between cervical smears and cervical carcinomas from HIV negative women $(P=0.553)$. These results suggest that JCV may combine with high-risk HPV infection in women infected with HIV to influence the rate of progression to invasive cervical carcinoma. J. Med. Virol.

(C) 2013 Wiley Periodicals, Inc.
\end{abstract}

KEY WORDS: HPV; BK virus; JCV; immunocompromised; cervical cancer

\section{INTRODUCTION}

The JC polyomavirus (JCV) and BK polyomavirus (BKV) are ubiquitous in human populations worldwide with a seroprevalence of $70-80 \%$ in adults
[Khalili et al., 2006; Knowles, 2006]. Primary infections are typically subclinical and probably occur early in childhood, followed by viral dissemination to sites of lifelong persistent latent infection, which are most commonly the kidney and central nervous system for both JCV and BKV [Heritage et al., 1981; Chesters et al., 1983]. Subsequent activation of these viruses can produce serious diseases including polyomavirus nephropathy and progressive multifocal leukoencephalopathy [Gardner et al., 1971; Markowitz et al., 1993]. However, the factors which control the balance between latency and disease-associated reactivation are poorly defined, although immunosuppression clearly plays a role since BKV and JCV related diseases are more common in transplant recipients and HIV-infected individuals [Behzad-Behbahani et al., 2004].

JCV is considered the etiological agent of progressive multifocal leukoencephalopathy (PML) [Wang et al., 2011]. AIDS is the most common underlying cause of immunosuppression leading to JCV reactivation, while BKV is associated with hemorrhagic cystitis in hematopoietic stem cell transplantation (HSCT) recipients and interstitial nephropathy in immunocompromised kidney transplant patients [Kinnaird and Anstead, 2010].

It has been clearly demonstrated that glial cells in the central nervous system are productively infected by both JCV and HIV-1. The striking similarity of AIDS and PML leukoencephalopathy suggests that JCV reactivation is a consequence of HIV infection, either by HIV-encoded trans-acting factors or through T4 cell depletion [Kaniowska et al., 2006]. Evidence

Grant sponsor: King Fahad Medical City, Riyadh, Saudi Arabia

${ }^{*}$ Correspondence to: Ian N. Hampson, Viral Oncology Laboratories, University of Manchester Institute of Cancer Sciences, Research Floor 5, St. Mary's Hospital, Manchester M13 9WL, UK. E-mail: ian.hampson@manchester.ac.uk

Accepted 11 December 2013

DOI 10.1002/jmv.23868

Published online in Wiley Online Library

(wileyonlinelibrary.com). 
for a direct role for HIV in JCV activation has been provided by studies which showed that the JCV late promoter can be transactivated by the HIV-1 Tat protein [Del Valle et al., 2000; Qu et al., 2004].

The current study was prompted by the work of Comar et al. [2011] who showed that BKV was found more frequently in Italian women with high-grade squamous intraepithelial lesions in association with high-risk human papillomavirus type 16 (HPV-16). However, these researchers did not examine cervical carcinomas from women in the same geographical location. For the first time, the authors now report analysis of the prevalence of BK and JC polyomaviruses in cervical smears and carcinomas from HIV positive and HIV negative Kenyan women.

\section{MATERIALS AND METHODS}

\section{Collection of Cervical Smear and Tumor Samples}

Between April 2008 and February 2009 at the Specialist HIV Clinic and Family Planning Clinic at Kenyatta National Hospital (Nairobi), 220 cervical smears samples were collected with written informed consent from $105 \mathrm{HIV}$ positive and $115 \mathrm{HIV}$ negative Kenyan women. The women ranged in age between 21 and 52 years (median age: 35 years) and those who had prior destructive procedures for cervical disease and hysterectomies were excluded. Cervical smears were collected into PreservCyt liquid based cytology (LBC) transport solution (ThinPrep Pap Test; Hologic, Crawley, West Sussex, UK). These were analyzed together with a total of 109 formalin fixed paraffin embedded (FFPE) tissue biopsies from women with invasive cervical carcinoma recruited at the same hospital. Thirty-seven of these cervical carcinomas were from HIV positive patients while 72 were from $\mathrm{HIV}$ negative patients. Both LBC and invasive cervical carcinoma specimens had their DNA extracted using the methods described below.

\section{Ethics Statement}

Ethical approval was granted by both the Kenyatta National Hospital and University of Nairobi's Ethics Review Board (05.12.2007: KNH-ERC/01/4988) and the Oldham Ethics Committee UK (26.01.2009: amendment five project 07/Q1405/14).

\section{DNA Extraction}

All study patients underwent an HIV test using the Determine ${ }^{\circledR}$ test kit (Abbot Pharmaceuticals, Chicago, IL), and if positive, was confirmed by UniGold $^{\mathbb{R}}$ (Trinity Biotech, Bray, Ireland). Automated DNA extraction was performed on $500 \mu$ l of all 220 PreserveCyt LBC samples with the use of BioRobot ${ }^{\mathbb{R}}$ M48, (Qiagen, Sussex, UK) according to the manufacturer's instructions. Approximately $4 \times 10 \mu \mathrm{l}$ (FFPE) invasive cervical carcinomas sections were cut using single-use disposable microtome blades and disposable forceps for section handling. DNA isolation was carried out using the Qiagen Qiacube FFPE kits (Qiagen) as described by the manufacturer.

\section{Genomic DNA Integrity Validation}

The integrity of each DNA sample was validated by detection of the housekeeping gene glyceraldehyde 3-phosphate dehydrogenase (GAPDH) (NCBI accession number: NM_002046). The forward primers sequence: CATTGĀCCTCAACTACATGGT; reverse primer sequence: TCGCTCCTGGAAGATGGTGAT generate amplicons of $130 \mathrm{bp}$. Standard $50 \mu \mathrm{l}$ reactions were prepared which comprised $2 \mu \mathrm{l}$ of $25 \mathrm{ng} / \mu \mathrm{l}$ template DNA, 2.5units of Taq DNA polymerase (Qiagen), 0.2 mM dNTPs, $0.2 \mu \mathrm{M}$ of each primer, $5 \mu \mathrm{l}$ $10 \times$ PCR buffer, and $2.5 \mathrm{mM} \mathrm{MgCl}_{2}$. Thermocycler conditions were $94^{\circ} \mathrm{C}$ for $5 \mathrm{~min}$ followed by 33 cycles of $94^{\circ} \mathrm{C}$ for $25 \mathrm{sec}, 53^{\circ} \mathrm{C}$ for $25 \mathrm{sec}, 72^{\circ} \mathrm{C}$ for $25 \mathrm{sec}$; and a final extension of $72^{\circ} \mathrm{C}$ for $7 \mathrm{~min}$. All reactions were performed on a VerityH 96-well Fast Thermocycler.

Twenty microliters of PCR product was loaded into $2 \% \mathrm{w} / \mathrm{v}$ agarose gels (SeaKemH LE Agarose; Lonza, Biologics, Tewkesbury, Gloucestershire, UK) and separated by agarose gel electrophoresis (Clarit-E Maxi electrophoresis tanks, Alpha Laboratories, Eastleigh, UK) at $100 \mathrm{~V}$ for $45 \mathrm{~min}$. DNA was visualized using ethidium bromide and imaged on a UVP M-20 Gel documentation system (UVP, Cambridge, Cambs, $\mathrm{UK})$.

\section{Sensitivity of the Nested PCR}

Primers (PYV) were designed to detect a conserved $\mathrm{N}$-terminal region of the polyomavirus large $\mathrm{T}$ gene from both BK and JC viruses (Table I). The sensitivity of this assay was evaluated by using a 100 $10^{-9} \mathrm{ng}$ serial dilution of plasmid containing the JC large $\mathrm{T}$ open reading frame $(\mathrm{ORF})$.

\section{Nested PCR Detection of BK and JC Virus}

The outer PYY primer set [Martini et al., 2004] amplifies a conserved 181 base pair (bp) long fragment from both BKV and JCV. The inner primer sets amplify a $77 \mathrm{bp}$ long fragment of BKV and $75 \mathrm{bp}$ of JCV, respectively. A $2 \mu \mathrm{l}$ aliquot of the primary PYY

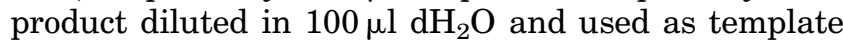
for the secondary internal nested PCR.

Reactions were performed in a total volume of $50 \mu \mathrm{l}$ containing $2 \mu \mathrm{l}$ of DNA template, $0.2 \mu \mathrm{M}$ of each primer, $0.2 \mathrm{mM}$ dNTPs, $2 \mu \mathrm{l} \mathrm{MgCl}_{2}, 10 \mu \mathrm{l}$ of $5 \times$ GoTaq Green buffer, and $1.25 \mathrm{U}$ of Platinum Taq DNA polymerase (GoTaq ${ }^{\circledR}$ Hot Start Polymerase; Promega, Southampton, Hamps, UK).

PCR conditions were $95^{\circ} \mathrm{C}$ for 2 min HotStart activation followed by 40 cycles for primary PYY amplification and 30 cycles for the secondary nested virus specific amplification (Table I). Cycle conditions were; $94^{\circ} \mathrm{C}$ for $30 \mathrm{~s}, 58^{\circ} \mathrm{C}, 72^{\circ} \mathrm{C}$ for $30 \mathrm{~s}$ and a final 
TABLE I. PCR Primers Used and Their Amplicons

\begin{tabular}{|c|c|c|c|c|}
\hline Primer type & Oligo name & To detect & Sequences $\left(5^{\prime}-3^{\prime}\right)$ & Amplicon size (bp) \\
\hline \multirow[t]{2}{*}{ Nested outer primers } & PYV.for & BKV and JCV & TAGGTGCCAACCTATGGAACAGA & \multirow[t]{2}{*}{181} \\
\hline & PYV.rev & BKV and JCV & GAAAGTCTTTAGGGTCTTCTACC & \\
\hline \multirow[t]{2}{*}{ Nested inner primers } & BKS2.for & BKV & AAGAAGCAACAGCAGATTCT & \multirow[t]{2}{*}{77} \\
\hline & BKS2.rev & $\mathrm{BKV}$ & GAAAGTCTTTAGGGTCTTCTACC & \\
\hline \multirow[t]{2}{*}{ Nested inner primers } & JCVS2.for & JCV & ATGATGAAAACACAGGATCC & \multirow[t]{2}{*}{75} \\
\hline & JCVS2.rev & JCV & GAAAGTCTTTAGGGTCTTCTACC & \\
\hline
\end{tabular}

extension at $72^{\circ} \mathrm{C}$ for $5 \mathrm{~min}$. PCR products were performed on a VerityH 96-well Fast Thermocycler. Twenty milliliters of PCR product was loaded into $2 \% \mathrm{w} / \mathrm{v}$ agarose gels and separated by agarose gel electrophoresis at $90 \mathrm{~V}$ for $45 \mathrm{~min}$. DNA was visualized using ethidium bromide and imaged on a UVP Transilluminator (Fig. 1).

\section{Statistical Analysis}

Statistical analyses were performed using the chi-square test for comparative statistical analysis between group frequencies, using IBM SPSS statistics 20 version. In order to assess the significance levels between the categorical variables, values $P<0.05$ were regarded statistically significant.

\section{RESULTS}

\section{Validation of JCV-BKV PCR Methods}

The sensitivity limit of the assay was shown to be $10^{-7} \mathrm{ng}$ of input plasmid DNA which is equivalent to an input of 18 copies of the JC/BK ORF per reaction.

\section{BKV-JCV DNA Screening}

Twenty-four out of 329 cervical specimens $(7.3 \%)$ were shown to contain BKV-JCV DNA. Control plasmids containing JCV and BKV were used as positive controls for PCR amplification and $\mathrm{dH}_{2} \mathrm{O}$ was used a negative control.

The first Pan PYV PCR was carried out using JCV-BKV consensus primers (Table I) and in most cases a single 181-bp fragment was amplified from both the cervical smear and cervical carcinoma samples coincident with the positive control (Fig. 2A and $\mathrm{B})$. The second nested PCR was performed with the JCV and BKV specific primers using the Pan PVY PCR products as input material. A single JCspecific 77-bp amplimer was produced from all 24 Pan PYV positive samples, whereas none were positive for BKV (Fig. 2C and D).

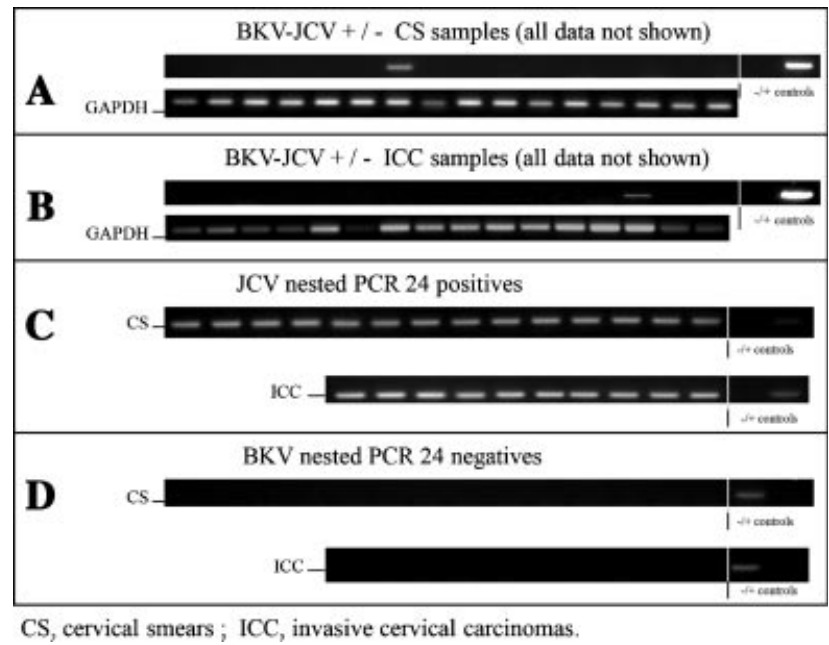

Fig. 2. PCR detection of JCV and/or BKV. A and $\mathbf{B}$ : The first PCR was carried out using JCV-BKV consensus primers which amplified a single 181-bp amplimer from 24 samples out of the 329 tested C: Nested PCR was performed as described on these positive samples using JCV specific primers which gave a single 77-bp amplimer from all 24 sample samples tested. D: Nested PCR on the same $181 \mathrm{bp}$ product with BKV specific primers gave no signal.

\section{Presence of JCV or BKV DNA in Cervical Smears and Cervical Carcinoma Specimens}

The overall prevalence of PYV DNA in cervical specimens was 24/329 (7.3\%) which were all confirmed to be JCV. The overall proportion of JCV positives in cervical smears $(6 \%)$ and cervical carcinomas (9\%), are shown in Table II, with no significant difference in JCV infection between these two groups $(P>0.05)$.

\section{The Association Between JCV and HPV Infection in Cervical Smears and Cervical Carcinomas}

The cervical smears and cervical carcinoma samples used in this study have been previously analyzed for the presence of various HPV types using Papillocheck

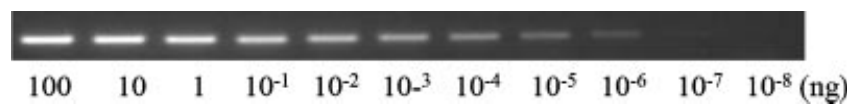

Fig. 1. Ethidium bromide stained agarose gel showing a titration of the sensitivity of the PCR amplification of the $181 \mathrm{bp}$ JCV-BKV PCR product. 
TABLE II. Rate of JCV Infection Found in CS and ICC

\begin{tabular}{lccccccc}
\hline & \multicolumn{2}{c}{$\mathrm{JCV}+$} & & \multicolumn{2}{c}{$\mathrm{JCV}-$} & & \\
\cline { 2 - 3 } Samples & No. & $\%$ & & No. & $\%$ & Total & $P$-value \\
\hline CS & 14 & 6 & 206 & 94 & 220 & $>0.05$ \\
ICC & 10 & 9 & 99 & 91 & 109 & \\
Total & 24 & 7 & & 305 & 93 & 329 & \\
\hline
\end{tabular}

SC, cervical smears; ICC, invasive cervical carcinomas.

HPV genotyping and dual locus multiplex PCRs respectively as described in Maranga et al. [2012]. The HPV data from this earlier study were analyzed with respect to JCV status and the results are shown in Table III. Within the HPV16/18 positives, JCV infection was found in 5 of 122 cervical smears (4\%), and in 4 of 59 cervical carcinomas $(6.7 \%)$; while in the HPV16/18 negatives, 9 of 115 cervical smears $(6.6 \%)$ and 6 of 60 cervical carcinomas (10\%) were JCV positive (Table III). Although all cervical smears and cervical carcinoma samples which were positive for JCV were also positive for a "high-risk" oncogenic HPV type, analyses of these data showed that there was no significant association between JCV and HPV16/18 in any group $(P>0.05)$. Analysis of cervical cytology showed that although there was an increase in JCV infection in HIV infected women with cervical dysplasia, this did not achieve statistical significance.

\section{The Association Between JCV and HIV Infection in Cervical Smears and Cervical Carcinomas}

As for HPV analysis, the HIV status of the women used in this study has also been previously reported [Maranga et al., 2012]. For HIV negative women, JCV DNA was detected in $9 / 115(7.8 \%)$ of the cervical smears and in $4 / 72(5.5 \%)$ of the cervical carcinomas, which was not statistically significant $(P>0.05)$. However, for HIV positive women, JCV DNA was detected in 5/105 (4.7\%) of the cervical smears and in $6 / 37(16 \%)$ of the cervical carcinomas (Fig. 3, $P<0.05$ ). This suggests there may be a significant association between JCV and cervical carcinoma, but only in HIV positive women.

\section{DISCUSSION}

There is now a general acceptance that viruses play a key role in the pathogenesis of many types of human cancer [Rwazavian, 2011] and it is thought that they promote malignant transformation by generating genetic instability in infected cells [Giuliani et al., 2008]. Polyomaviruses are capable of inducing chromosomal instability [Dolcetti et al., 2003] and although the role of polyomaviruses in carcinogenesis is still controversial, they have been linked to the etiology of various human malignancies [White et al., 2005]. The major transforming protein of polyomaviruses is the large $\mathrm{T}$ tumor antigen ( $\mathrm{T}-\mathrm{Ag}$ ) which plays a key role in the deregulation of the cell cycle through interaction with the p53 and pRb tumor suppressor proteins [zur Hausen, 2008].

In the current study, it was tested whether there was an association between the polyomaviruses JC and BK and different stages in the development of cervical cancer in HIV infected and non-infected Kenyan women. Previous studies have reported on the presence of $\mathrm{BKV}$ and $\mathrm{JCV}$ in urogenital carcinomas [Monini et al., 1995; Comar et al., 2011], which suggested that these viruses may act as cofactors in the etiology of these malignancies. Indeed, Comar et al. [2011] reported that 44\% (41/93) of HPV16 positive high-grade cervical intraepithelial neoplasias (HSILs) were positive for BKV in Italian women. These data are consistent with the hypothesis that co-infection with two or more different diseasecausing organisms in one individual can facilitate the disease process [Operskalski and Kovacs, 2011].

JCV sequences have been detected in various tissues including kidneys, brain, liver, lung, spleen, lymph nodes, and colorectal epithelium [Easha et al., 2006; Jiang et al., 2009]. In addition to its role in PML, JCV has been previously shown to be associated with several human malignancies such as colorectal, central nervous system (CNS) lymphoma, glioblastomas, and pediatric medulloblastomas; although its role in brain tumors remains controversial [Reiss and Khalili, 2003; Khalili et al., 2006; zur Hausen, 2008; Collins et al., 2011; Rwazavian, 2011].

These data clearly show detection of JCV and not BKV sequences in samples derived from the female genitalia which is a potential latent site for polyomavirus infection [Martini et al., 2004] (see Fig. 2). This finding also suggests that, whilst closely related, JCV and BKV may hold different geographical evolutionary histories and infers the predominance of JCV within African populations. Indeed, JCV infection rates are known to vary among populations being influenced by geographical area and ethnic origin and it has been suggested that JCV may be a bio-anthropological

TABLE III. Analyses of the Association Between JCV and HPV Infections

\begin{tabular}{|c|c|c|c|c|c|c|}
\hline \multirow[b]{2}{*}{ Infections } & \multicolumn{2}{|c|}{$\mathrm{CS}$} & \multirow[b]{2}{*}{$P$-value } & \multicolumn{2}{|c|}{ ICC } & \multirow[b]{2}{*}{$P$-value } \\
\hline & HPV16/18+ & HPV16/18- & & HPV16/18+ & HPV16/18- & \\
\hline $\begin{array}{l}\text { JCV+ } \\
\text { JCV- }\end{array}$ & $\begin{array}{r}5 \\
117\end{array}$ & $\begin{array}{r}9 \\
106\end{array}$ & $>0.05$ & $\begin{array}{r}4 \\
55\end{array}$ & $\begin{array}{r}6 \\
44\end{array}$ & $>0.05$ \\
\hline
\end{tabular}

SC, cervical smears; ICC, invasive cervical carcinomas. 


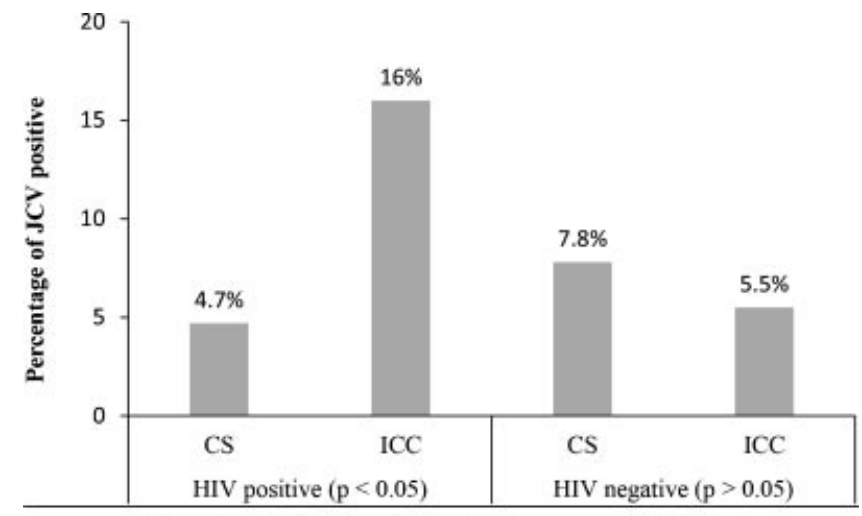

$\mathrm{CS}$, cervical smears ; ICC, invasive cervical carcinomas.

Fig. 3. Analysis of the association between JCV and HIV infection. The frequency of JCV infection in cervical carcinomas was significantly higher in HIV positive cervical carcinomas than that in any of the other groups tested irrespective of HIV status $(P<0.05)$.

marker that is useful for studying the early migration of human populations around the world [CayresVallinoto et al., 2012]. Furthermore, based upon sequence analysis of the major capsid protein (VP1), JCV can be divided into a number of subtypes $(n>14)$ which also have distinctive geographic distributions. Modern Homo sapiens originated in Africa and it is possible that JCV may have co-diverged with migratory human populations over many thousands of years [Guo et al., 1996; Shackelton et al., 2006].

In this investigation no significant association was observed between the frequency of JCV virus and HPV16/18 (Table III). It has been shown previously that HIV infection alters the spectrum of HPV types found in both cervical smears and invasive cervical carcinomas which suggests a complex interplay between these viruses during progression to cervical cancer [Maranga et al., 2012]. The precise molecular interactions underlying co-infection with HPV in HIV positive women and how this influences progression from cervical dysplasia to invasive cervical carcinoma is not straightforward and requires clarification. For example it is generally assumed that HIV related immunosuppression will facilitate the oncogenic effects of HPV by enhancing its persistence and, as a consequence, oncogenic progression [Mandelblatt et al., 1999]. However, previous work has also suggested this may be an over simplification whereby HIV could enhance infection with some types of HPV which might actually retard progression [Maranga et al., 2012].

Clearly the present results do not support a role for JCV in the etiology of cervical cancer in HIV negative women. However, the finding of three times the rate of JCV infection in cervical carcinomas from women infected with HIV when compared to HIV negative women is intriguing. It is possible this could be causally related to the etiology of cervical carcinomas or alternatively this could be a bystander event associated with other HIV/AIDS related pathologies. With the current data set it is not possible to distinguish between these two possibilities and this will form the basis of further work. Indeed reactivation of latent polyomaviruses is known to accompany AIDS associated immunosuppression [Boothpur and Brennan, 2010]. Furthermore, several studies have documented urinary excretion of JCV and BKV in HIV positive patients suggesting that polyomavirus reactivation is a feature of HIV infection [Markowitz et al., 1993; Behzad-Behbahani et al., 2004; Knowles, 2006] and it seems reasonable to propose JCV as a sexually transmissible viral agent. Moreover, in association with cellular proteins, the HIV-1 Tat protein is known to bind to the JCV non-coding region to stimulate JCV transcription and replication [Wright et al., 2013]. HIV is well known to increase the risk of cancers associated with other viruses best exemplified by the ability of HIV-1 tat protein to promote the growth of human herpes virus-8 (HHV-8) associated Kaposi's sarcoma [Pyakurel et al., 2007].

Martini et al. [2004] reported a simultaneous association of polyomaviruses with human genital tumors and suggested their involvement as a cofactor in the onset/progression of cervical cancer. Mechanistically, genetic instability induced by T-Ag is likely to be an important contributor to polyomavirus-induced oncogenesis. Furthermore, it has been shown that JCV T-Ag dysregulates $\beta$-catenin signaling in some colon cancers and medulloblastoma [Enam et al., 2002] and the T-Ag also binds and degrades p53 via ubiquitination thus deregulating the cell cycle and inhibiting apoptosis [White and Khalili, 2004].

In conclusion, based on the present results, it is possible that JCV may act synergistically with HPV and HIV to facilitate the transformation of cervical epithelium in some Kenyan women. However, since the majority of these HIV positive women will develop cervical carcinoma in the absence of JCV it is quite clear that more work is needed to define the potential role of this virus in the etiology of invasive cervical carcinomas in this population.

\section{ACKNOWLEDGMENTS}

We acknowledge support from the Saudi Arabian Cultural Bureau in London (to Bandar). Work in the Viral Oncology Labs was also supported by the Humane Research Trust, The Caring Cancer Trust, The Cancer Prevention Research Trust, and United in Cancer.

\section{REFERENCES}

Behzad-Behbahani A, Klapper PE, Vallely PJ, Cleator GM, Khoo SH. 2004. Detection of BK virus and JC virus DNA in urine samples from immunocompromised (HIV-infected) and immunocompetent (HIV-non-infected) patients using polymerase chain reaction and microplate hybridisation. J Clin Virol 29:224-229.

Boothpur R, Brennan DC. 2010. Human polyoma viruses and disease with emphasis on clinical BK and JC. J Clin Virol 47: 306-312. 
Cayres-Vallinoto IMV, Vallinoto ACR, Azevedo VN, Almeida Machado LF, Guimaraes Ishak MdO, Ishak R. 2012. Human JCV infections as a bio-anthropological marker of the formation of Brazilian amazonian populations. PLoS ONE 7.

Chesters PM, Heritage J, McCance DJ. 1983. Persistence of DNAsequences of $\mathrm{BK}$ virus and JC virus in normal human-tissues and in diseased tissues. J Infect Dis 147:676-684.

Collins D, Hogan AM, Winter DC. 2011. Microbial and viral pathogens in colorectal cancer. Lancet Oncol 12:504-512.

Comar M, Bonifacio D, Zanconati F, Di Napoli M, Isidoro E, Martini F, Torelli L, Tognon M. 2011. High prevalence of BK polyomavirus sequences in human papillomavirus-16-positive precancerous cervical lesions. J Med Virol 83:1770-1776.

Del Valle L, Croul S, Morgello S, Amini S, Rappaport J, Khalili K. 2000. Detection of HIV-1 Tat and JCV capsid protein, VP1, in AIDS brain with progressive multifocal leukoencephalopathy. J Neurovirol 6:221-228.

Dolcetti R, Martini F, Quaia M, Gloghini A, Vignocchi B, Cariati R, Martinelli M, Carbone A, Boiocchi M, Tognon M. 2003. Simian virus 40 sequences in human lymphoblastoid B-cell lines. J Virol 77:1595-1597.

Easha S, Manley K, Gasparovic M, Querbes W, Atwood WJ. 2006. The human polyomaviruses. Cell Mol Life Sci 63:865-876.

Enam S, Del Valle L, Lara C, Gan DD, Ortiz-Hidalgo C, Palazzo JP, Khalili K. 2002. Association of human polyomavirus JCV with colon cancer: Evidence for interaction of viral T-antigen and beta-catenin. Cancer Res 62:7093-7101.

Gardner S, Field A, Coleman D, Hulme B. 1971. New human papovavirus (B.K.) isolated from urine after renal transplantation. Lancet 297:1253-1257.

Giuliani L, Ronci C, Bonifacio D, Di Bonito L, Favalli C, Perno CF, Syrjanen K, Ciotti M. 2008. Detection of oncogenic DNA viruses in colorectal cancer. Anticancer Res 28:1405-1410.

Guo J, Kitamura T, Ebihara H, Sugimoto C, Kunitake T, Takehisa J, Na YQ, AlAhdal MN, Hallin A, Kawabe K, Taguchi F, Yogo Y. 1996. Geographical distribution of the human polyomavirus $\mathrm{JC}$ virus types $\mathrm{A}$ and $\mathrm{B}$ and isolation of a new type from Ghana. $\mathrm{J}$ Gen Virol 77:919-927.

Heritage J, Chesters PM, McCance DJ. 1981. The persistence of papovavirus BK DNA-sequences in normal human renal tissue. J Med Virol 8:143-150.

Jiang M, Abend JR, Johnson SF, Imperiale MJ. 2009. The role of polyomaviruses in human disease. Virology 384:266-273.

Kaniowska D, Kaminski R, Amini S, Radhakrishnan S, Rappaport J, Johnson E, Khalili K, Del Valle L, Darbinyan A. 2006. Crossinteraction between JC virus agnoprotein and human immunodeficiency virus type 1 (HIV-1) tat modulates transcription of the HIV-1 long terminal repeat in glial cells. J Virol 80:92889299.

Khalili K, Gordon J, White MK. 2006. The polyomavirus, JCV, and its involvement in human disease. Adv Exp Med Biol 577:274287.

Kinnaird AN, Anstead GM. 2010. Hemorrhagic cystitis and possible neurologic disease from BK virus infection in a patient with AIDS. Infection 38:124-127.
Knowles WA. 2006. Discovery and epidemiology of the human polyomaviruses BK virus (BKV) and JC virus (JCV). Adv Exp Med Biol 577:19-45.

Mandelblatt JS, Kanetsky P, Eggert L, Gold K. 1999. Is HIV infection a cofactor for cervical squamous cell neoplasia? Cancer Epidemiol Biomarkers 8:97-106.

Maranga IO, Hampson L, Oliver AW, He X, Gichangi P, Rana F, Opiyo A, Hampson IN. 2012. HIV infection alters the spectrum of HPV subtypes found in cervical smears and carcinomas from Kenyan women. Open Virol J 6:121-129.

Markowitz RB, Thompson HC, Mueller JF, Cohen JA, Dynam WS 1993. Incidence of BK-virus and JC-virus viruria in human immunodeficiency virus-infected and virus-uninfected subjects. J Infect Dis 167:13-20.

Martini F, Iaccheri L, Martinelli M, Martinello R, Grandi E, Mollica G, Tognon M. 2004. Papilloma and polyoma DNA tumor virus sequences in female genital tumors. Cancer Invest 22:697-705.

Monini P, Rotola A, Diluca D, Delellis L, Chiari E, Corallini A, Cassai E. 1995. DNA rearrangements impairing BK virus productive infection in urinary-tract tumors. Virology 214:273279.

Operskalski EA, Kovacs A. 2011. HIV/HCV co-infection: Pathogenesis, clinical complications, treatment, and new therapeutic technologies. Curr HIV/AIDS Rep 8:12-22.

Pyakurel P, Pak F, Mwakigonja AR, Kaaya E, Biberfeld P. 2007. KSHV/HHV-8 and HIV infection in Kaposi's sarcoma development. Infect Agent Cancer 2:4.

Qu QM, Sawa H, Suzuki T, Semba S, Henmi C, Okada Y, Tsuda M, Tanaka S, Atwood WJ, Nagashima K. 2004. Nuclear entry mechanism of the human polyomavirus JC virus-like particleRole of importins and the nuclear pore complex. J Biol Chem 279:27735-27742.

Reiss K, Khalili K. 2003. Viruses and cancer: Lessons from the human polyomavirus, JCV. Oncogene 22:6517-6523.

Rwazavian N. 2011. Can a virus cause cancer: A look into the history and significance of oncoviruses. Berk Sci J 14.

Shackelton LA, Rambaut A, Pybus OG, Holmes EC. 2006. JC virus evolution and its association with human populations. J Virol 80:9928-9933.

Wang TS, Byrne PJ, Jacobs LK, Taube JM. 2011. Merkel cell carcinoma: Update and review. Semin Cutan Med Surg 30: $48-56$.

White MK, Khalili K. 2004. Polyomaviruses and human cancer: Molecular mechanisms underlying patterns of tumorigenesis. Virology 324:1-16.

White MK, Gordon J, Reiss K, Del Valle L, Croul S, Giordano A Darbinyan A, Khalili K. 2005. Human polyomaviruses and brain tumors. Brain Res Brain Res Rev 50:69-85.

Wright CA, Nance JA, Johnson EM. 2013. Effects of Tat proteins and Tat mutants of different human immunodeficiency virus type 1 clades on glial JC virus early and late gene transcription. J Gen Virol 94:514-523.

zur Hausen H. 2008. Novel human polyomaviruses-Re-emergence of a well known virus family as possible human carcinogens. Int J Cancer 123:247-250. 